\title{
Commentary Predictors of outcome in myxoedema coma
} Jennifer Beynon, Simeen Akhtar and Tara Kearney

Endocrinology Department, Salford Royal NHS Foundation Trust, Stott Lane, Salford, M6 8HD, UK

Corresponding author: Jennifer Beynon, jenniferarnott@doctors.org.uk

Published: 23 January 2008

This article is online at http://ccforum.com/content/12/1/111

(c) 2008 BioMed Central Ltd

See related research by Dutta et al, http://ccforum.com/content/12/1/R1
Critical Care 2008, 12:111 (doi:10.1186/cc6218)

Due to the rarity of myxoedema coma, very few randomised controlled trials have been undertaken to look at the treatment and outcome; however, myxoedema coma remains an important entity to diagnose. The prevalence of hypothyroidism is likely to increase with advancements in diagnostic tools and the increased practice of offering definitive treatment for hyperthyroidism in the form of radioactive iodine treatment and thyroidectomy. Clinicians need to have a high index of clinical suspicion to make an early diagnosis when myxoedema coma is present. Mortality has fallen from $80 \%$ to $20 \%-40 \%$ in treated individuals partly due to increased awareness of physicians, improved diagnostic testing, and advances in intensive care [3]. However, these statistics are based on developed countries and Dutta and colleagues raise a pertinent point in highlighting the differences in the developing world, where ready access to laboratory tests is not always possible and education for the primary physician, who does not have to deal with large numbers of thyroid conditions, remains important.

It is evident that these patients need to be treated in an intensive care setting with close monitoring of their cardiovascular status. Ventilatory support is often needed because of decreased level of consciousness, respiratory depression secondary to drugs, underlying pneumonia, or sometimes macroglossia or myxoedema of the larynx resulting in airway obstruction [3]. Hypothermia, besides conventional treatment with warm blankets and fluids, requires replacement with thyroid hormones to normalise thermoregulation. There is consensus that all patients should be given glucocorticoids as these patients may have coexistent adrenal insufficiency; thyroid hormone replacement may result in increased metabolism of cortisol, thereby precipitating adrenal crisis. However, controversy regarding optimal replacement regimens persists due to the paucity of large clinical trials [6-10]. Three different regimens have been advocated: (a) intravenous (IV) or oral $\mathrm{T}_{4}$, (b) IV $\mathrm{T}_{3}$, or (c) a combination of $\mathrm{T}_{4}$ and

$\mathrm{IV}=$ intravenous; $\mathrm{T}_{3}=$ triiodothyronine; $\mathrm{T}_{4}=$ thyroxine; $\mathrm{TSH}=$ thyroid-stimulating hormone. 
$\mathrm{T}_{3}$. Unfortunately, the work of Dutta and colleagues has not moved the debate forward with a definite answer; no clinical or biochemical differences were observed between those patients who initially received IV compared with oral $\mathrm{T}_{4}$. Arlot and colleagues [6] demonstrated that although oral absorption of levothyroxine was variable, the clinical response occurred promptly, even in a case of myxoedema ileus. A prospective study by Rodríguez and colleagues [7] found that the administration of higher doses of levothyroxine appeared to reduced mortality, although statistical significance was not reached. All studies are limited by small sample size.

Predictors of poor outcome in patients with myxoedema coma include increased age, cardiovascular compromise, and reduced consciousness. In the study by Rodríguez and colleagues [7], mortality rates for both primary and secondary hypothyroidism were similar and survival was independent of the mean free $\mathrm{T}_{4}$ and TSH concentrations. The analysis of Dutta and colleagues of de novo subjects compared with treatment defaulters is interesting epidemiologically and again highlights the importance of education. Nevertheless, this information is not useful in determining the outcome once the patients have reached the intensive care setting, unlike the SOFA (Sepsis-related Organ Failure Assessment) score, which provides a more dynamic approach in predicting outcome by regularly analysing six systems, namely respiration, cardiovascular, liver, coagulation, renal, and neurological [11].

\section{Competing interests}

The authors declare that they have no competing interests.

\section{References}

1. Dutta P, Bhansali A, Masoodi S, Bhadada S, Sharma N, Rajput R: Predictors of outcome in myxoedema coma: a study from a tertiary care centre. Crit Care 2008, 12:R1.

2. Nicoloff JT: Thyroid storm and myxedema coma. Med Clin North Am 1985, 69:1005-1017.

3. Wartofsky L: Myxedema coma. Endocrinol Metab Clin North Am 2006, 35:687-698.

4. Fliers E, Wiersinga WM: Myxedema coma. Rev Endocr Metab Disord 2003, 4:137-141.

5. Benvenga S, Squadrito S, Saporito F, Cimino A, Arrigo F, Trimarchi $F$ : Myxedema coma of both primary and secondary origin, with non-classic presentation and extremely elevated creatine kinase. Horm Metab Res 2000, 32:364-366.

6. Arlot S, Debussche X, Lalau JD, Mesmacque A, Tolani M, Quichaud J, Fournier A: Myxoedema coma: response of thyroid hormones with oral and intravenous high-dose L-thyroxine treatment. Intensive Care Med 1991, 17:16-18.

7. Rodríguez I, Fluiters E, Pérez-Méndez LF, Luna R, Páramo C, Garcia-Mayor RV: Factors associated with mortality of patients with myxoedema coma: prospective study in 11 cases treated in a single institution. $J$ Endocrino/ 2004, 180:347-350.

8. Hylander B, Rosenqvist U: Treatment of myxoedema comafactors associated with fatal outcome. Acta Endocrinol (Copenh) 1985, 108:65-71.

9. Yamamoto T, Fukuyama J, Fujiyoshi A: Factors associated with mortality of myxedema coma: report of eight cases and literature survey. Thyroid 1999, 9:1167-1174.

10. Pereira VG, Haron ES, Lima-Neto N, Medeiros-Neto GA: Management of myxedema coma: report on three successfully treated cases with nasogastric or intravenous administration of triiodothyronine. J Endocrinol Invest 1982, 5:331-334.

11. Vincent JL, Moreno R, Takala J, Willatts S, De Mendonça A, Bruining H, Reinhart CK, Suter PM, Thijs LG: The SOFA (Sepsis- related Organ Failure Assessment) score to describe organ dysfunction/failure. On behalf of the Working Group on Sepsis-Related Problems of the European Society of Intensive Care Medicine. Intensive Care Med 1996, 22:707-710. 